\title{
Comercio, integración y competencia en la perspectiva latinoamericana*
}

\section{Trade, integration and competition in the latin american perspective}

\section{Jorge Witker**}

SUMARIO: I. Introducción. II. Los tratados de integración. III. Los TLC's y las clausulas referidas a la competencia en la región. IV. Colusión-cartelización derivadas de los TLC's por omisión de cláusula de competencia. V. Cartelización de la producción y servicios internacionales. VI. Órganos reguladores de la Competencia en la región. VII. Conclusiones. VIII. Bibliografía.

* Artículo recibido el 23 de febrero de 2011 y aceptado para su publicación el 29 de junio de 2011.

** Investigador en el Instituto de Investigaciones Jurídicas de la UNAM; iunvestigador nacional nivel III del Sistema Nacional de Investigadores. El autor agradece la valiosa colaboración de la licienciada Ivonne Nohemi Díaz Madrigal en la realización de este artículo. 
RESUMEN: La integración es un proceso económico y dinámico, con consecuencias sociales y políticas, que implican la interacción comercial, financiera, social, cultural, política, gradual y progresiva entre los Estados. Se deriva de una necesidad en la era de la globalización, que responde a la integración del mercado. La creciente apertura comercial, la existencia de una legislación pro-competencia y una ausencia de leyes punitivas, conduce a la colusión entre las empresas con el objetivo de la fijación de precios. Esto impide el progreso hacia el crecimiento económico y el desarrollo para los consumidores nacionales, a quienes deberían beneficiar estos procesos.

Palabras clave: integración, globalización, colusión, competencia económica.

ABSTRACT: Integration is a dynamic economic process, with social and political consequences, which imply the interplay of trade, finance, social, cultural, political, gradual and progressive among states. That derives from a necessity in the era of globalization, which responds to market integration. The increasing trade openness, the existence of pro-competition legislation and an absence punitive laws, leads to collusion among companies with the objective of price fixing. This prevents progress towards economic growth and development for domestic consumers, who should benefit these processes.

Descriptors: integration, globalization, collusion, economic competition

RÉSUMÉ: L'intégration est un processus économique et dynamique, avec des conséquences sociales et politiques, qui impliquent l'interaction commerciale, financière, social, culturelle, politique, graduelle et progressive entre les États. Il se dérive d'une nécessité dans l'ère de la mondialisation, qui répond à l'intégration du marché. L'ouverture commerciale croissante, l'existence d'une législation favorable à la concurrence et un manque de lois punitives, conduit à la collusion entre les entreprises avec l'objectif de la fixation des prix. Cette situation empêche les progrès vers la croissance économique et le développement pour les consommateurs nationaux, qui devraient se voir bénéficiés de ces processus.

Mots-Clés: l'intégration, la mondialisation, la collusion, la concurrence économique. 


\section{INTRODUCCIÓN}

El presente artículo, previo a reflexionar sobre los conceptos de integración y globalización, analiza los procesos de integración - cerrados y abiertos - que ha experimentado Latinoamérica, señalando que en general, los tratados de libre comercio hasta el momento celebrados, no regulan ni sancionan prácticas monopólicas. Al abrirse las economías, las grandes empresas monopólicas aprovechan indiscriminadamente sus posiciones dominantes, con lo cual no se avanza hacia el crecimiento y desarrollo económico para los consumidores nacionales, a quienes estos procesos deben favorecer.

La integración, es un proceso económico y dinámico, con consecuencias sociales y políticas, que implican la interrelación comercial, financiera, social, cultural, política, gradual y progresiva entre Estados. Deriva de una necesidad estatal en la era de la globalización, que responde a una integración de mercados. ${ }^{1}$

Hasta la fecha sólo se han identificado características de los tipos de procesos de integración, sin que exista una definición unificada respecto al término integración económica. Sobre el particular Bela Belassa realiza la siguiente reflexión: ${ }^{2}$

En su uso cotidiano la palabra integración denota la unión de las partes de un todo. En la literatura económica el término integración económica no tiene un significado tan claro, algunos autores la incluyen dentro del concepto de integración social, otras agrupan las diferentes formas de cooperación internacional bajo este encabezado, y la argumentación se ha desarrollado tanto que la mera existencia de relaciones comerciales entre las economías nacionales independientes se ha tomado como un signo de integración.

En efecto, la complejidad que involucra, nos posiciona en la connotación de una dinámica económica inmersa en el fenómeno de la globali-

1 De la concepción gramatical del concepto integración, podemos afirmar que su aplicabilidad se traduce en varios complejos y transformantes contextos entre los que se encuentran los siguientes contextos: político, jurídico, ideológico, cultural, geográfico, sociológico, religioso, económico, militar y otros.

2 Véase Bela Belassa, J. D., Teoría de la integración económica, México, UTEHA, 1943. 
zación. De esta forma, "la integración es como un proceso, mediante el cual, dos o más actores, forman un nuevo actor". ${ }^{3}$

De esta forma, podemos afirmar que la integración, es un proceso económico que pretende disminuir y suprimir la discriminación entre unidades económicas de diferentes naciones, donde la cooperación es un primer estadio que conforma escenarios económicos que permitan un libre intercambio de bienes, servicios, capital, tecnología, etcétera, a través de instituciones y normatividades supranacionales. ${ }^{4}$

En el contexto del fenómeno actual de la globalización, encontramos como singularidades el retiro estratégico del Estado de las actividades económicas ${ }^{5}$ y la apertura de los mercados nacionales a la competencia internacional. ${ }^{6}$

Así, los protagonistas del mercado global - las empresas - construyen los escenarios de actuación conforme a sus intereses y pueden ser ajenas a lo dispuesto en las políticas públicas estatales, pues su rol depende de las opciones empresariales que nacional o trasnacionalmente asumen. ${ }^{7}$

Ahora bien, globalización e integración, jurídicamente son procesos diferentes. El fenómeno global lo protagonizan las empresas en escenarios de mercados globales, mientras la integración la protagonizan los Estados, bajo tratados internacionales regulados por el conocido derecho de los tratados. ${ }^{8}$

3 Véase Oropeza García, Héctor Arturo, México-Mercosur: un nuevo diálogo para la integración, México, UNAM-Centro Argentino para las Relaciones Internacionales, 2002, p. 25.

4 Witker Jorge, El derecho de la competencia económica en el TLCAN, México, Porrúa-UNAM, 2003, pp. 5 y ss.

5 Pellicer, Olga, “Las relaciones de México con el exterior: un breve diagnóstico”, en Herrera Lasso, Luis (coord.), México ante el mundo. Un tiempo de definiciones, México, Fondo de Cultura Económica, 2006, pp. 42-48.

6 Gilpin, Robert, Global Political Economy Understanding the International Economic Order, Princeton, Princeton University Press, 2001, pp. 17 y ss.

7 De Venanzi Augusto, Globalización y corporación. El orden social en el siglo XXI, Barcelona, Anthropos, 2002, pp. 81 y ss.

8 Sobre el particular se recomienda consultar la Convención de Viena sobre el Derecho de los Tratados de 1969, www.derechos.org/nizkor/ley/viena.html. 


\section{LOS TRATADOS DE INTEGRACIÓN}

La globalización que jurídicamente se expresa en la región a través de numerosos tratados de libre comercio - expresión de lo que se ha denominado regionalismo abierto_-, implica o supone una apertura de mercados y escenarios de libre competencia que erosionan todos los intentos proteccionistas sobre los cuales los Estados cobijan sus respectivos crecimientos industriales. Esta perspectiva de deber ser de las economías abiertas, sin embargo, ha evidenciado efectos no deseados, puesto que en ninguno de los tratados de libre comercio de esta categoría, se han regulado expresamente las prácticas monopólicas de las empresas, sus concentraciones, colusiones ni los cárteles por ellas formados. Es decir, aprovechando el repliegue de la actuación estatal (con el retiro de las empresas públicas) han entrado a los mercados nacionales con posiciones dominantes, perjudicando a grandes como a medianas empresas nacionales y a consumidores en general. Es por lo anterior que se debe postular desde ya, necesarias agencias reguladoras de la competencia en la región a fin de limitar estas prácticas que a nivel internacional tanto Estados Unidos, Unión Europea, Brasil y Chile en nuestra región, lo han estado legislando y sancionando, como veremos en el último apartado.

Los procesos de integración en el mundo han estado vinculados a esquemas regulados o fronterizos entre naciones o espacios geográficos acotados. Dentro del rubro de tratados regionales, el siglo XX fue testigo en América, de la formación de dos tipos de regionalismos, uno encabezado por la Comisión Económica para América Latina (CEPAL), y otro por Estados Unidos.

Dentro del primer regionalismo, la CEPAL esbozó los elementos esenciales para la integración regional, ejemplo de ello fue el Estudio Económico para América Latina de 1949, intensificando su acción promotora hasta la suscripción de la Asociación Latinoamericana de Libre Comercio (ALALC) en $1960 .{ }^{9}$

El descenso del ritmo en las exportaciones entre 1953 y 1955 fue la ocasión propicia para plantear políticamente las iniciativas de integración

\footnotetext{
9 Véase Prebisch, Raúl, Hacia una nueva política comercial para el desarrollo, México, Fondo de Cultura Económica, 1960, pp. 23 y ss.
} 
de la CEPAL. La primera reunión del Comité de Comercio, celebrada en noviembre de 1956, inició una etapa de esclarecimiento y negociación que culminó en 1959, luego de una serie de reuniones de diversos órganos técnicos y políticos convocados y promovidos por la CEPAL, precisándose así la propuesta, objetivos e instrumentos de la formula regional, conocida como Mercado Regional Latinoamericano, que fue restringida conforme avanzaron las negociaciones en la ALALC.

A lo largo de las negociaciones encabezadas por la CEPAL, se insistió en la conveniencia de avanzar poco a poco en acuerdos con las distintas condiciones de los países y se destacó la necesidad de flexibilizar los instrumentos, a través del establecimiento de cláusulas de escape o salvaguardias, apoyando en esta primera etapa del regionalismo una zona preferencial de comercio. ${ }^{10}$

Una de las razones por las cuales la CEPAL recomendaba un avance prudente, era sus insistencia en que el proceso integrador debía tener alcances latinoamericanos. De igual forma señaló que el mercado común debería dar iguales oportunidades para acelerar el desarrollo de todos y cada unos de los países participantes, e insistió en mantener la necesidad de un tratamiento preferencial para los países de desarrollo incipiente. ${ }^{11}$

No obstante este esfuerzo significativo realizado por la CEPAL, al final, la ALALC terminó conformando un proceso más ambicioso, al establecer una zona de libre comercio, en lugar de la creación de un régimen preferencial para el intercambio de productos entre sus países.

\section{Regionalismo cerrado: $A L A L C-A L A D I$}

El fenómeno de la sucesión de organismos de integración, implica la sustitución de determinadas zonas preferenciales, ${ }^{12}$ por otras más ade-

10 Clement, Norris, North American Economic Integration. Theory and practice, MA. EU, North Hampton, 1999, pp. 12 y ss.

${ }^{11}$ Calva, José Luis, México, Más allá del neoliberalismo, México, Plaza y Janes, 2000, pp. 22 y ss.

12 Cuyo desarrollo se ha estancado, o que resultan obsoletas para la prosecución de los objetivos originales. 
cuadas a las características de los países involucrados y sus prioridades. Tal fenómeno puede realizarse de manera automática ${ }^{13}$ o gradual. En el primer caso, existe un periodo de transición, en el cual ambas organizaciones tienen vigencia simultánea. Esta transición puede ser regulada por normas resultado de la voluntad de todos los países involucrados o asumir la forma de una "fade-out", donde no existe vinculación jurídica entre el acuerdo que pierde vigencia y aquel destinado a reemplazarlo. El nuevo acuerdo prevé y regula la adhesión de los países integrantes de la nueva zona, en un periodo preestablecido. ${ }^{14}$

En el segundo caso, cuando la sucesión es regulada por normas emanadas de la voluntad conjunta de todos los países involucrados, la constitución de la nueva zona preferencial es el resultado de un proceso que se desarrolla en el seno mismo de la organización sustituida, a través de resoluciones emanadas de sus órganos. Es el caso de la sucesión de la ALALC, por la ALADI. ${ }^{15}$ El proceso de sucesión inició en el seno mismo de la ALALC, ${ }^{16}$ participando todos sus miembros y mediante resoluciones dictadas por sus propios órganos, las cuales pertenecían al orden jurídico nacional de las partes y no requerían para entrar en

13 Ejemplo de ello es el artículo 15 del Tratado Constitutivo de la OECD, que en 1961 sustituye a la OEEC.

14 Un ejemplo de esta forma de sucesión lo es la de la Asociación de Libre Comercio del Caribe (CARFTA) por la Caribbean Community (CARICOM) en general, y al Mercado Común del Caribe en un Mercado Común en Estado naciente, en lo particular.

15 El artículo 2o. del Tratado de Montevideo de 1960, constitutivo de la ALALC disponía la creación de una zona de libre comercio a concretarse al cabo de un periodo de doce años (plazo que se cumplía en 1972), mismo que se prolongó al 31 de diciembre de 1980, mediante la firma del Protocolo de Caracas. No obstante, se tuvo que ampliar nuevamente el plazo, para que finalmente el 12 de agosto de 1980 se firma el Tratado de Montevideo, constitutivo de la ALADI.

16 El 18 de febrero de 1960 se firmó en la ciudad de Montevideo el Tratado de Montevideo por el cual las partes contratantes acuerdan la creación de la Asociación Latinoamericana de Libre Comercio (ALALC). Firmaron el Tratado Argentina, Brasil, Chile, México, Paraguay, Perú y Uruguay, adhiriéndose posteriormente Colombia (30 de septiembre de 1961), Ecuador (3 de noviembre de 1961), Venezuela (31 de agosto de 1966) y Bolivia (8 de febrero de 1967). La propuesta de "integración acelerada", un proyecto integracionista supranacional patrocinado por Chile, Venezuela y Colombia, fue derrotada por el bloque de Argentina, Brasil y México, que consiguió hacer prevalecer su concepción de un proceso de integración "gradual" y dependiente de los desarrollos nacionales. El último bloque recibió el decisivo respaldo de los representantes de Bolivia, Paraguay y Uruguay. 
vigor, ratificación. No se podía esperar que la transición se regulara por el nuevo Tratado, ni por un protocolo adicional al tratado a sustituirse, pues estos hubieran requerido la ratificación de los países signatarios para ingresar en sus ordenamientos nacionales. ${ }^{17}$

El objetivo de ALALC fue la constitución de una zona de libre comercio dentro de un determinado plazo. ${ }^{18}$ Durante este periodo debían eliminarse gradualmente todos los gravámenes y restricciones que obstaculizaran el intercambio comercial ${ }^{19}$ entre las partes contratantes. ${ }^{20}$

A fin de perfeccionar la zona de libre comercio, se previó que la eliminación de gravámenes y restricciones de todo orden, para lo esencial del comercio recíproco, debía llevarse a cabo por medio de negociaciones periódicas en el curso de doce años. Componían el Programa de Liberación del intercambio dos tipos de listas: nacionales (de cada uno de los países miembros) y una lista común. ${ }^{21}$ Las concesiones otorgadas sobre productos incluidos en la lista común debían ser irrevocables, en tanto las incorporadas a las listas nacionales podían ser retiradas previa negociación y adecuada compensación. Un mecanismo considerado como complementario del Programa de Liberación fue el de los acuerdos de complementación, que podían acelerar la reducción de gravámenes y demás restricciones para los productos negociados en ellos. Eran órganos de la Asociación: el Consejo de Ministros de Relaciones Exteriores, la Conferencia y el Comité Ejecutivo Permanente.

17 Hummer, Waldemar y Prager, Dietmar, GATT, ALADI y NAFTA, Buenos Aires, Ciudad Argentina, 1998, pp. 66 y ss.

18 Originalmente se establecieron doce años que se prolongaron a veinte.

19 Este proceso se llevaría a cabo mediante negociaciones periódicas a través del mecanismo de listas: las "listas nacionales" y la "lista común".

20 El excesivo optimismo produjo un estancamiento en el progreso de las negociaciones e inviabilizó los esfuerzos de integración. La escasa actividad entró en una situación de estancamiento. Éste y otros factores condujeron a la resolución de poner en marcha el mecanismo de su reestructura y a la decisión de los Estados miembros de rectificar un nuevo tratado, que dio origen a la ALADI (Asociación Latinoamericana de Integración), que reemplazo a la ALALC.

21 En las listas nacionales se incluirían todas las concesiones que cada parte contratante otorgaba al resto de la zona, es decir, contenía ventajas concedidas, en virtud del principio de la nación más favorecida, por cada país miembro de la ALALC a los restantes, pudiendo retirar productos de esas listas cuando el país que otorgó la concesión enfrentara dificultades económicas. La lista común se negociaba multilateralmente cada tres años. Los productos incluidos en la lista común no podían ser objeto de restricciones no arancelarias ni de cupos. 
La Asociación Latinoamericana de Integración Económica (Aladi 1980), es el bloque de integración comercial más importante de América Latina, integrado por Argentina, Bolivia, Brasil, Chile, Colombia, Cuba, Ecuador, México, Paraguay, Perú, Uruguay y Venezuela. Propicia la creación de un área de preferencias económicas en la región, con el objetivo final de lograr un mercado común latinoamericano dentro del marco jurídico del Tratado de Montevideo de 1980, mediante tres mecanismos:

- Una preferencia arancelaria regional que se aplica a productos originarios de los países miembros frente a los aranceles vigentes para terceros países.

- Acuerdos de alcance regional (comunes a la totalidad de los países miembros).

- Acuerdos de alcance parcial, con la participación de dos o más países del área. ${ }^{22}$

Tanto los acuerdos regionales como los de alcance parcial $^{23}$ pueden abarcar materias diversas como desgravación arancelaria y promoción del comercio; complementación económica; comercio agropecuario; cooperación financiera, tributaria, aduanera, sanitaria; preservación del medio ambiente; cooperación científica y tecnológica; promoción del turismo; normas técnicas, y muchos otros aspectos previstos a título expreso o no en el Tratado de Montevideo. ${ }^{24}$ Por lo que éste constituye un "tratadomarco".

Los países calificados de menor desarrollo económico como Bolivia, Ecuador y Paraguay, gozan de un sistema preferencial. A través de las nóminas de apertura de mercados que los países ofrecen a favor de los países menos desarrollados; de programas especiales de cooperación (ruedas de negocios, preinversión, financiamiento, apoyo tecnológico); y de medidas compensatorias a favor de los países mediterráneos, se

22 Kitamura, Hiroshi, “Teoría Económica y la Integración en las Regiones Subdesarrolladas”, en Wionczek, Miguel S., Integración de América Latina, México, FCE, 1979.

23 Artículos 6o. a 9o. del Tratado de Montevideo.

24 Artículos 10 a 14 del Tratado de Montevideo. 
busca una participación plena de dichos países en el proceso de integración.

El Tratado de Montevideo (1980), estuvo abierto a la adhesión de cualquier país latinoamericano. De hecho, el 26 de julio de 1999 la República de Cuba formalizó ante el gobierno de Uruguay — país sede del organismo - el depósito del instrumento de adhesión, constituyéndose en el doceavo miembro pleno el 26 de agosto del mismo año.

La Aladi abre además su campo de acción hacia el resto de América Latina mediante vínculos multilaterales o acuerdos parciales con otros países y áreas de integración del continente tal y como lo establece el artículo 25 del Tratado:

Asimismo, los países miembros podrán concertar acuerdos de alcance parcial con otros países y áreas de integración económica de América Latina, de acuerdo con las diversas modalidades previstas en la sección tercera del capítulo II del presente Tratado, y en los términos de las respectivas disposiciones reglamentarias.

Sin perjuicio de lo anterior, estos acuerdos se sujetarán a las siguientes normas:

a) Las concesiones que otorguen los países miembros participantes, no se harán extensivas a los demás, salvo a los países de menor desarrollo económico relativo;

b) Cuando un país miembro incluya productos ya negociados en acuerdos parciales con otros países miembros, las concesiones que otorgue podrán ser superiores a las convenidas con aquéllos, en cuyo caso se realizarán consultas con los países miembros afectados con el fin de encontrar soluciones mutuamente satisfactorias, salvo que en los acuerdos parciales respectivos se hayan pactado cláusulas de extensión automática o de renuncia a las preferencias incluidas en los acuerdos parciales a que se refiere el presente artículo; y

c) Deberán ser apreciados multilateralmente por los países miembros en el seno del Comité a efectos de conocer el alcance de los acuerdos pactados y facilitar la participación de otros países miembros en los mismos.

Asimismo contempla la cooperación horizontal con otros movimientos de integración del mundo y acciones parciales con terceros países en vías de desarrollo o sus respectivas áreas de integración. ${ }^{25}$

25 Artículo 27 del Tratado de Montevideo. 
La Aladi da cabida en su estructura jurídica a otros acuerdos subregionales, plurilaterales y bilaterales de integración que surgen en forma creciente en el continente (Comunidad Andina de Naciones, Grupo de los Tres, Mercosur, etcétera). En consecuencia, le corresponde a la Asociación — como marco o "paraguas" institucional y normativo de la integración regional_ desarrollar acciones tendientes al apoyo y fomento de estos esfuerzos, con la finalidad de hacerlos confluir progresivamente en la creación de un espacio económico común.

Dentro del marco de la Aladi, México ha suscrito los acuerdos de complementación económica siguientes:

- El Acuerdo de Complementación Económica núm. 6 México-Argentina, suscrito el 13 de octubre de 1993. Publicado en el Diario Oficial de la Federación el 19 de abril de 1999.

- El Acuerdo de Complementación Económica núm. 53, MéxicoBrasil, suscrito el 3 de julio de 2002, entró en vigor el 2 de mayo de 2003 y tendrá una vigencia hasta que sea sustituido por un nuevo acuerdo entre México y Mercosur.

- El Acuerdo de Complementación Económica con Perú.

- El Acuerdo de Complementación Económica con Cuba.

- Acuerdos de Complementación Económica con el Mercosur en el sector automotriz.

- El Acuerdo de Complementación Económica núm. 60, entre México y Uruguay, que para fines de la OMC, es el Tratado de Libre Comercio entre México y Uruguay

Dentro de este contexto, hasta 2008 México — según datos publicados en el Boletín de junio de 2008, emitido por la Secretaría de Económia - se posicionó como el principal inversionista de América del Sur. Entre los principales sectores a los que se ha orientado la participación de capitales mexicanos en el exterior se encuentran la minería, agrobiotecnología, producción de alimentos, cemento, textiles, llantas, prestación de servicios de telecomunicaciones (telefonía fija y móvil e Internet), televisión por cable y financieros. ${ }^{26}$

26 Brasil es el principal destino de las inversiones mexicanas en la región, donde aumentaron $62 \%$, al acumular 16545 millones de dólares en 2007, concentrados principalmente en los sectores de telecomunicaciones y alimentos. 
De acuerdo a estimaciones realizadas por la Secretaría General, el monto total de las importaciones intrarregionales se ubicó, al finalizar el 2005, en el entorno de los US\$ 76000 millones, lo que representa un record histórico en el intercambio comercial. En 2003 dicha cifra ascendía a US\$ 44900 millones, en circunstancias que en 1980, año de la creación de la Aladi, el comercio intrarregional alcanzó los US\$12 000 millones. ${ }^{27}$ Sus exportaciones han superado a Canadá, India y Oceanía;

Al cierre de 2008, se espera la llegada de nuevas inversiones en otros sectores como el de las tecnologías de la información y servicios financieros.

El segundo destino de las inversiones mexicanas es Colombia, donde el aumento en 2007 fue de 1800 millones de dólares, cifra 60\% superior a la alcanzada hasta diciembre de 2006, desplazando a Venezuela al tercer sitio que se mantuvo prácticamente sin movimiento.

Los flujos de capital mexicano a Colombia colocan a México en el sexto lugar como inversionista extranjero en ese país. Dichas inversiones están concentradas en sectores como alimentos, construcción, telecomunicaciones y automotriz.

Perú tuvo un incremento de 100 millones de dólares y se mantuvo en la cuarta posición. En Chile y Ecuador, las inversiones aumentaron en torno al 30\%, con valores en 2007 de 600 y 320 millones de dólares, respectivamente.

En el caso de Chile, a pesar de ser un mercado relativamente pequeño (15 millones de consumidores) para los empresarios mexicanos es un país atractivo por su estabilidad política, reglas claras y amplia apertura comercial.

En 2007, el incremento de la inversión mexicana en Chile se realizó fundamentalmente en telefonía móvil donde se acumuló activos por 825 millones de dólares, consolidándose junto con la telefonía fija e Internet como los principales sectores de inversión mexicana en ese país.

Así, México se ubica entre los diez principales inversionistas en Chile, en una lista que encabeza Estados Unidos y España.

En Argentina, no obstante que no hubo registro de nuevas inversiones en 2007, durante los últimos años la llegada de capital mexicano a esta nación ha registrado un crecimiento sostenido, triplicando el valor de 2002. El interés de empresas mexicanas por instalarse en Argentina ha generado un clima que en el corto plazo prevé que las inversiones recíprocas crecerán aún más.

Las inversiones en los sectores de alimentos y bebidas, comunicaciones, construcción y servicios financieros concentran casi el $90 \%$ del total invertido en ese país.

En Venezuela, el acumulado de 4300 millones de dólares, convierten a México en el primer inversionista latinoamericano. Las empresas mexicanas se desempeñan en sectores como el de alimentos y bebidas, construcción, metalmecánica y comunicaciones. Representación Permanente de México ante la ALADI, Boletín México Exporta, núm. 7, Secretaría de Economía, www.aladi.org, consultado el 28 de agosto de 2008.

27 http://www.ibce.org.bo/ComExt/comex 140-1.htm 
de 1980 a 2006 se incrementaron a 65000 millones. De 2001 a 2006 crecieron 63\%, de 40000 a 65000 millones. ${ }^{28}$

\section{Regionalismo abierto:TLCAN}

Este proceso regional de integración, materializa desde la perspectiva mexicana, frutos del segundo regionalismo observado en América Latina, que se materializa con la adhesión de Estados Unidos a los compromisos regionales en detrimento de los multilaterales, algunos autores han catalogado la conversión de este país al artículo XXIV del GATT en el catalizador del segundo regionalismo, en referencia al iniciado por la CEPAL en la conformación, de la ALALC.

Durante los años noventa, del siglo XX la integración latinoamericana ha venido encuadrándose en una estrategia que la CEPAL ha denominado regionalismo abierto y que lo contextualiza de la siguiente manera: en contraste con el ambiente de escepticismo que enfrentaban los esquemas formales de integración económica en América Latina y el Caribe durante los decenios de los ochenta, en los noventa proliferan acuerdos de diversa índole y muy heterogéneos, en cuanto a sus modalidades y configuración geográfica. Así lo demuestran las iniciativas tendientes a formar zonas de libre comercio, uniones aduaneras, mercados comunes. ${ }^{29}$

Dentro de este contexto, se suscribe el Tratado de Libre Comercio de América del Norte, entre Canadá, Estados Unidos y México, que entró en vigor en el 1o. de enero de 1994, tratado que en realidad es una adhesión al tratado ya existente entre Estados Unidos y Canadá, iniciando así, una nueva era en materia comercial para nuestro país.

Los objetivos del tratado, de acuerdo con el artículo 102 son:

28 Presentación de Juan Acuña, secretario general de la Aladi, realizada en Santiago de Chile, noviembre de 2008 y disponible en www.eclac.org/comercio/noticias/paginas/9/34499/ Juan_Acuna.pdf.

29 Alperstein Lerman, Aida, Multilateralismo y Regionalismo en América Latina, México, Porrúa-UAM, p. 73. 
a) Eliminar obstáculos al comercio y facilitar la circulación transfronteriza de bienes y servicios entre los territorios de las partes.

b) Promover condiciones de competencia leal en la zona de libre comercio.

c) Aumentar sustancialmente las oportunidades de inversión en los territorios de las partes.

d) Proteger y hacer valer, de manera adecuada y efectiva, los derechos de propiedad intelectual en el territorio de cada una de las partes.

e) Crear procedimientos eficaces para la aplicación y cumplimiento del tratado, su administración conjunta y la solución de controversias.

f) Establecer lineamientos para la ulterior cooperación trilateral, regional y multilateral encaminada a ampliar y mejorar los beneficios del tratado.

Los principios del tratado que se abordan en los 22 capítulos y sus anexos son los siguientes:

- Trato nacional. Uno de los aspectos más sustanciales del tratado es que bienes, servicios y personas deben ser considerados como originarios de los respectivos países suscriptores delTLCAN. Así, una mercancía canadiense debe ser considerada en territorio mexicano como originaria de México. Es decir, no es viable discriminar por razones de nacionalidad. La única excepción a este principio la encontramos en el capítulo VI del tratado, aunque los minerales radiactivos mexicanos excluyen tajantemente la presencia de canadienses y estadounidenses en su explotación en territorio nacional. ${ }^{30}$

- Trato de nación más favorecida. Este principio general del GATTOMC significa que cualquier convenio comercial o de servicio que las partes delTLCAN efectúen bilateralmente debe extenderse automáticamente a la otra parte. Este principio está subordinado al artículo XXIV del Acuerdo General de Aranceles y Comercio, que

30 Decisiones e informes del TLCAN, http:/www.naft-sec-alena.org/spanish/decisión/fta/ index.htm, consulta realizada el 12 de octubre de 2010. 
permite que grupos de países que forman una zona de libre comercio o unión aduanera puedan temporalmente excluir a terceros países de los beneficios de la cláusula de nación más favorecida.

- Transparencia. Este principio, expresamente establecido en el capítulo XVIII del tratado, obliga a los tres países a notificar toda modificación, reforma o adición que se intente efectuar a las legislaciones internas y que se relacionan con aspectos regulados por el tratado, a fin de prevenir o evitar controversias entre operadores económicos zonales. Dicho principio se complementa con el código de conducta (artículo 2009.2, inciso c), y con las reglas modelo de procedimiento (artículo 2012) del propio tratado.

Se estructura con un preámbulo y 22 capítulos distribuidos en ocho partes, las cuales tratan, respectivamente, de los siguientes temas:

- Primera parte. Aspectos generales: está integrada por los capítulos I y II que se ocupan de los objetivos del tratado y de las definiciones generales.

- Segunda parte. Comercio de bienes: conformada por los capítulos III a VIII, que versan acerca del trato nacional y acceso de bienes al mercado (capítulo III); reglas de origen (capítulo IV); procedimientos aduaneros (capítulo V); energía y petroquímica básica (capítulo VI); sector agropecuario y medidas sanitarias y fitosanitarias (capítulo VII), y medidas de emergencia (capítulo VIII).

- Tercera parte. Barreras técnicas al comercio: capítulo IX, relativo a las medidas en torno a la normalización.

- Cuarta parte. Compras del sector público: capítulo X, que se ocupa del tema enunciado.

- Quinta parte. Inversión, servicios y asuntos relacionados: la integran los capítulos XI a XVI que plantean los temas de inversión (capítulo XI); comercio transfronterizo de servicios (capítulo XII); telecomunicaciones (capítulo XIII); servicios financieros (capítulo XIV); política en materia de competencia, monopolios y empresas del Estado (capítulo XV), y entrada temporal de personas de negocios (capítulo XVI).

- Sexta parte. Propiedad intelectual: capítulo XVII. 
- Séptima parte. Disposiciones administrativas e institucionales: que incluye los capítulos XVIII a XX, que presentan la publicación, notificación y administración de leyes (capítulo XVIII); revisión y solución de controversias en materia de antidumping y cuotas compensatorias (capítulo XIX), y disposiciones institucionales y procedimientos para la solución de controversias (capítulo XX).

- Octava parte. Otras disposiciones: está integrada por los capítulos XXI y XXII que exponen las excepciones y las disposiciones finales, respectivamente.

- El tratado cuenta, además, con diversos anexos integrados a lo largo de su capitulado, así como de notas, el anexo 401 y siete anexos numerados del I al VII que van al final del texto.

A 17 años de la suscripción del Tratado de Libre Comercio, los beneficios prometidos aún no son muy tangibles. Ciertamente, el comercio entre los tres países ha crecido de manera significativa, pero el volumen de nuestras exportaciones contrasta con la importación de una importante cantidad de insumos para incorporar a los procesos productivos.

Tomando en cuenta que elTLCAN no es sólo un acuerdo de liberalización comercial, su evaluación no puede reducirse al análisis de la balanza comercial. Incluye, como lo hemos vivido en estos años de vigencia, un nuevo papel del Estado en la economía, nuevos marcos legales y derechos de los inversionistas extranjeros, y diferentes protecciones a la propiedad intelectual. Incluso en el ámbito comercial incluye nuevos ámbitos, adelantándose a los resultados de la Ronda de Uruguay del GATT, al incluir más plenamente los servicios y el sector agrícola.

Lo cierto es que elTLCAN aceleró la transición de México hacia una economía liberalizada, ${ }^{31}$ sin crear las necesarias condiciones para que los sectores público y privado respondieran a los choques económicos, sociales y ambientales de comerciar con dos de las mayores economías del mundo. Los más vulnerables ciudadanos de México han enfrentado un remolino de cambios más allá de su capacidad de control, o la de su gobierno. ${ }^{32}$

31 Véase Banamex, Review of the Economic Situation in Mexico, vol. LXIV, núm. 752, julio de 1998.

32 Addley, John, La promesa y la realidad del TLCAN: lecciones de México para el Hemisferio Occidental, enero de 2004. 
Uno de los temas con más expectativas para México, una vez formada la zona de libre comercio más grande del mundo, fue el relativo a la generación de empleos, y que el TLCAN no ha ayudado a la economía mexicana a mantenerse a la altura de la creciente demanda de puestos de trabajo. Los salarios reales de la mayoría de los mexicanos son actualmente más bajos que cuando no se contaba con el acuerdo trilateral.

En cuanto a la migración, no se ha controlado el flujo de mexicanos que se trasladan anualmente hacia Estados Unidos ${ }^{33}$ en busca de trabajo; por el contrario, se ha registrado un aumento sin precedentes en el número de emigrantes que pretenden laborar en ese país, ${ }^{34}$ pese a las excesivas medidas de control fronterizo. ${ }^{35}$

En síntesis, los aspectos positivos identificados, son los siguientes:

- Crecimiento de nuestras exportaciones, principalmente a Estados Unidos.

- Crecimiento de la captación de inversión extranjera.

- Reformas legislativas en torno a inversión extranjera, derechos de propiedad, legislación comercial y privatizaciones. ${ }^{36}$

- Impacto amortiguador durante la crisis de 1994.

- Acceso a instrumentos comerciales diversos.

- Cambio estructural de nuestra economía y no dependencia exclusiva de exportaciones petroleras.

Los aspectos negativos son los siguientes:

- Concentración en el incremento de las exportaciones en limitadas empresas.

33 Véase Gastélum Gaxiola, María de los Ángeles, Migración de los trabajadores mexicanos indocumentados a los Estados Unidos, México, UNAM, 1991, pp. 155 y ss.

34 http://www.iom.int/jahia/Jahia/cache/offonce/lang/en/pid/1674? entryId=20275, consultada el 12 de septiembre de 2010.

35 Véase Diaz-Muller, Luis (coord.), Seminario Permanente de Derechos Humanos, Jornadas sobre Globalización y Derechos Humanos, México, UNAM-Instituto de Investigaciones Jurídicas, varias obras publicadas (Jornadas I-IV).

36 García Delgado, Carlos, "El acuerdo migratorio México-Estados Unidos. Postura nacional de largo plazo", Los retos para la política exterior de México en la actual coyuntura, México, Instituto Matías Romero, Secretaría de Relaciones Exteriores, 2004, pp. 137 y ss. 
- Polarización de las estructuras y organizaciones industriales en México.

- Aún no somos competitivos en numerosas ramas productivas.

- El derrame tecnológico derivado de la apertura comercial muestra poca inserción en el sector doméstico.

- La economía mexicana depende fuertemente de la estadounidense. ${ }^{37}$

- Existencia de prácticas desleales asimétricas.

- Deterioro económico y social del sector agropecuario, el cual se ha visto invadido por productos sustitutos transgénicos y subvencionados, amén de manejos discrecionales de cupos de importación con tasa cero, asignados a sectores monopolistas industriales (maíz, café, lácteos, papas, cárnicos, etcétera).

- Desarticulación de cadenas productivas a costa de las pequeñas y medianas empresas mexicanas que han sido excluidas como exportadores indirectos.

- Venta de armas a bandas mexicanas de delincuencia organizada.

\section{Tratado del Triángulo del Norte ${ }^{38}$}

Tratado de Libre Comercio suscrito entre el Salvador, Guatemala, Honduras y México, el 29 de junio de 2000, y publicado en el Diario Oficial

37 Fajnzylber, Pablo y López, J. Humberto, El impacto de las remesas en el desarrollo de América Latina, en http://sisteresources.worldbank.org/INTLACINSPANISH/Resources/Rmemittance_and_ Development_Ch_1_Spa..pdf, consultada en octubre, 2010].

38 Este tratado, actualmente coexiste con el CAFTA.El Tratado de libre comercio entre Estados Unidos, Centroamérica y República Dominicana (CAFTA, por sus siglas en inglés: Dominican Republic-Central America Free Trade Agreement), inicio sus negociaciones a partir de 2003, fue firmado y ratificado en diferentes fechas por los países parte del tratado: El Salvador, 1o. de marzo de 2006; Honduras, 1 de abril, 2006; Nicaragua, 1o. de abril de 2006; Guatemala, 1o. de julio de 2006; República Dominicana, 1o. de marzo de 2007; Costa Rica, 1 de enero de 2009.

Este Tratado establece las reglas que normarán la relación comercial entre los países parte, a través de una zona para el intercambio de bienes y servicios. Así mismo CAFTA cuenta con veintidós capítulos, divididos cada uno en artículos. Dentro de los temas primordiales que CAFTA trata están el trato arancelario, reglas de origen, administración aduanera, obstáculos técnicos al comercio, medidas sanitarias y fitosanitarias, derechos de propiedad intelectual, derecho laboral, derecho ambiental y solución de controversias. Los objetivos principales de 
de la Federación el 14 de marzo de 2001. Establece una Zona de Libre Comercio, cuyos objetivos son:

- Estimular la expansión y diversificación del comercio de bienes y servicios.

- Promover condiciones de libre competencia.

- Eliminar las barreras al comercio y facilitar la circulación de bienes originarios y servicios.

- Eliminar las barreras al movimiento de capitales y personas de negocios.

- Aumentar las oportunidades de inversión.

- Proteger y hacer valer, de manera adecuada y efectiva, los derechos de propiedad intelectual.

- Establecer lineamientos, para la ulterior cooperación entre las partes, encaminados a ampliar y mejorar los beneficios del Tratado de Libre Comercio.

- Crear procedimientos eficaces para la aplicación y cumplimiento del tratado, su administración conjunta y solución de controversias.

Incorpora a nivel de disposiciones un esquema muy semejante al del TLCAN, ${ }^{39}$ de hecho contempla el comercio de servicios, y regula las mercancías, acceso a mercados, reglas de origen casi con disposiciones de alcance semejante. El regionalismo abierto legalizado en los tratados de libre comercio, que han seguido el esquema delTLCAN, en materia de libre competencia, no han aportado nada positivo en la región. Al no postular un rechazo a los monopolios y prácticas monopólicas a nivel de los mercados abiertos, ha insertado formas de colusión y/o cartelización de empresas, como lo veremos en las siguientes líneas de este artículo.

este tratado son la promoción del comercio dentro de la región CAFTA-DR, facilitación en la circulación transfronteriza de mercancías y servicios, fomento de la competencia leal y lo más importante generación de un ambiente apto para la promoción de inversión extranjera directa. http: / / www.vestex.com.gt $/ v x /$ index.php?option $=$ com_content\&view $=$ article\&id $=301$ \&Ite mid $=185$ \&lang $=$ es.

39 Cfr. Alba Vega, Carlos, "A Mexican Assessment of the North American Free Trade Agreement Negotiations: Issues and Prospects”, en Green, Roy E., The Enterprise for the Americas Initiative, Connecticut, Westport. Praeger, 1993. 
La política de competencia está referida a la legislación, jurisprudencia y órganos aplicadores y reguladores de las prácticas anticompetitivas en que pueden incurrir agentes públicos (licitación de concesiones) o privados (predación y/o colusión).

Las etapas en la política de competencia en la región, pueden agruparse cronológicamente de la siguiente forma:

- 1960 a 1980. No existe competencia bajo modelo proteccionista sustitutivo de importaciones.

- 1980 a 1994-95. Apertura mercados globales e inversiones extranjeras. TLCAN-OMC y TLC's

- 2000 al 2010. Libre Comercio como proceso que refuerza la cartelización de empresas y reformas legales anticolusión.

El paradigma central de las legislaciones de Argentina, Brasil, Colombia, Chile, Costa Rica y Perú, es el poder de mercado o poder dominante.

En general el poder dominante es el que puede ejercer una empresa o conglomerado (cártel), cuando tiene capacidad para fijar un precio por encima del costo marginal, en un mercado relevante, perjudicando a oferentes, demandantes y consumidores.

Las legislaciones señaladas evalúan en general la dominancia bajo la regla de la razón, en todo caso contempla las siguientes variables:

1) Definición del mercado relevante.

2) La existencia de una posición de dominio por parte de una empresa o grupo de empresas.

3) Un abuso de dicha posición de dominio (individual o colectiva) identificando la o las prácticas específicas anticompetitivas.

4) Medir sus efectos a nivel consumidores y de bienestar general.

5) Ponderar ganancias o pérdidas en materia de eficiencia estática o dinámica. Por ejemplo, la introducción de ventas atadas o contrato 
de exclusividad, puede en algunos casos, eficientar a una industria y beneficiar así a consumidores.

\section{Conductas reguladas}

Derivadas del poder dominante o de mercado, las legislaciones señaladas previenen, regulan y sancionan, tres grandes vertientes anticompetitivas:

1) Conductas verticales (ventas atadas, contratos exclusivos).

2) Conductas horizontales (predación y/o colusión).

3) Concentraciones derivadas de fusiones y adquisiciones de empresas.

El conjunto de estas conductas, que se supone conlleva la noción de conductas abusivas, puede presentarse como abuso de explotación y/o como abuso de exclusión.

En el abuso de explotación, se fijan altos precios o precios discriminados tanto a nivel de oferta como de demanda.

A nivel de demanda, por ejemplo, la imposición de precios a los proveedores, es una práctica frecuente del comercio minorista en la región, ya que es común que supermercados impongan precios de compra a los productores agrícolas que Brasil y Argentina han penalizado, pues se trata de un abuso oligopólico que perjudica a los consumidores y a la producción nacional.

El abuso de exclusión se manifiesta cuando la empresa se niega a vender sus productos o servicios a determinados clientes o distribuidores, incrementando costos de las empresas rivales (actuales o potenciales) o maneja precios predatorios.

Las tarifas de servicios públicos de monopolios privatizados en la región son ejemplos que impiden el crecimiento de la oferta de competidores, transporte, teléfono, agua potable.

En la región, se pueden identificar las siguientes conductas anticompetitivas: 

a) Discriminación de precios.
b) Introducción de precios excesivos.
c) Precios predatorios.
d) Limitación de ventas y compras.
e) Ventas atadas.
f) Descuentos por lealtad.
g) Incremento de costos de empresas rivales.
h) Uso anticompetitivo de derechos de propiedad.
i) Acuerdos verticales cuando una de las partes presenta una PD.
j) Negativa a vender/boicots (cuando la negativa es realizada por un grupo de empresas).

En las legislaciones señaladas, las conductas anticompetitivas de tipo horizontal más frecuentes son la predación de precios, y la colusión, que con ocasión de la ampliación de los mercados y los propios Tratados de Libre Comercio han, en parte, estimulado en la región.

\section{COlusión. CARTElización DERIVADAS DE los TLC'S POR OMISIÓN DE CLÁUSULA DE COMPETENCIA}

Las colusiones son una práctica anticompetitiva horizontal, que consisten en acuerdos explícitos o tácitos, para aumentar precios o fijar cantidades (cuotas, reparto de clientes, distribución de zonas o regiones, etcétera), que las legislaciones latinoamericanas consideran castigable per se. Es considerada una conducta monopólica absoluta que impide la competencia en el mercado, y que a nivel mundial se conoce como cartelización. En las legislaciones estadounidense y de la Unión Europea lo están penalizando drásticamente.

En el caso de las concentraciones por fusiones y adquisiciones, la concentración de empresas no tuvo mayor importancia en la región, en el periodo histórico entre 1960-1980. A partir de la década de los noventa, las fusiones y adquisiciones adquieren relevancia por las privatizaciones de empresas y servicios públicos y por los procesos de apertura económica legalizada en los Tratados de Libre Comercio. 
Con fundamento en lo anterior, la inversión extranjera ha venido a jugar un papel clave en este proceso y ha acentuado la concentración económica, vulnerando en parte las políticas de competencia que impulsaron originalmente los TLC's.

Respecto a las notificaciones de fusiones, en las legislaciones señaladas, hay dos sistemas: ex ante y ex post. Es preciso evaluarlos cuidadosamente, pues afectan o pueden afectar directa o indirectamente la competencia de los mercados, aunque en algunos casos pueden ser procompetitivos en materia de eficiencia dinámica (servicios).

En los tratados de libre comercio y las políticas de competencia, la regulación internacional, de la competencia es uno de los asuntos, que al interior del GATT-OMC, mayor interés ha despertado en el último tiempo. Ello se debe a la constatación de que los esfuerzos internacionales y regionales de liberación comercial, se ven limitados en la actuación de agentes privados o gubernamentales, o en la mezcla de ambos.

La posición dominante de mercado y prácticas predatorias de precios, incluyendo colusiones, han estado presentes en la región, derivado de la ampliación de los mercados resultante de las liberaciones comerciales, grandes conglomerados trasnacionales por presencia y conductas, lo que en conjunto impide el acceso de nuevos agentes o vía fusionesadquisiciones, controlan mercados relevantes amparados en la libertad de inversión que acompañan los tratados de libre comercio.

Una breve revisión de los Tratados de Libre Comercio de la región nos señala que la mayoría no tiene cláusulas referidas a la penalización de prácticas anticompetitivas, como lo expresa el siguiente cuadro de acuerdos de libre comercio:

1. México
- Costa Rica

- AELC

- Unión Europea

- Japón

- Israel

- Nicaragua

- Triángulo del Norte (El Salvador, Nicaragua, Honduras)

- Uruguay

- Bolivia 
2. Chile

- AELC

- Unión Europea

- Corea

- México

- Estados Unidos

3. Centroamérica

- Chile

- República Dominicana

- Panamá

4. Canadá

- Chile

- Costa Rica

5. Otros

- CARICOM- Costa Rica

- De los tres: Colombia, Venezuela y México (G-3)

- Panamá- -Taiwán

De todos estos tratados, el único que contiene sanción expresa para las prácticas abusivas de posición dominante de conglomerados, es el Tratado de Libre Comercio Corea-Chile. En los otros se hace mención a las empresas o monopolios públicos, que deben actuar bajo criterios de racionalidad privada, y establecen coordinación e intercambio informativo para las agencias reguladoras de la competencia (ningún tratado hace mención a la información confidencial).

\section{CARTELIZACIÓN DE LA PRODUCCIÓN Y SERVICIOS INTERNACIONALES}

La política de competencia en el mundo, ha ido experimentando cambios, y las respectivas legislaciones para dar cuenta de las alteraciones a la libre competencia derivadas de la propiedad intelectual que legaliza posiciones dominantes, a los titulares de marcas, patentes, franquicias etcétera, de enorme presencia en los comercios mundiales de mercancías y servicios.

En función de esta nueva situación la política de competencia de corte tradicional, se ve limitada por las innovaciones tecnológicas que realizan permanentemente las grandes empresas especialmente en el sector far- 
macéutico, telecomunicaciones, transportes y otros rubros propios de la llamada nueva economía o economía simbólica.

Consecuencia de lo anterior, las legislaciones comparadas, especialmente, anglo-estadounidense y europeas, enfrentan los fenómenos descritos, con medidas que atacan las colusiones, que los cárteles y conglomerados internacionales practican en el mercado ampliado de la globalización. Estados Unidos ha logrado desarticular colusiones en vitaminas, grafitos y otros productos, como veremos a continuación.

\section{El cártel electrodos de grafito}

El electrodo de grafito es un insumo empleado para la producción de acero, sobre todo en los procesos de reciclaje de materia de desecho. El volumen de este mercado alcanzaba en 1998 los 420 millones de euros y más de 1200 millones de dólares estadounidenses. Dicho cártel se componía por 8 firmas con base en Alemania, Estados Unidos y Japón, cuya operación se extendió entre 1992 y 1996. El papel del cártel consistía a grosso modo en acordar precios de venta y reparto de mercado, al igual que eliminar descuentos y acordar restricciones en la capacidad de producción de los miembros. Dicha acción permitió que el precio de este producto se elevara en un $60 \%$ en promedio, en la mayoría de los mercados, dando lugar a la apertura de investigaciones en Estados Unidos y la Unión Europea, condenando a las firmas participantes en dicho cártel en 2001. En Europa la sanción alcanzó un total de 218.8 millones de euros, mientras que en Estados Unidos el monto fue de 410 millones de dólares más el encarcelamiento de dos ejecutivos.

En Europa, la firma Showka logró una reducción en la sanción del $70 \%$ (amnistía o delación compensada) a través de su colaboración en la investigación, proporcionando evidencia para probar la existencia del cártel.

\section{El cártel de vitaminas}

Este cártel internacional abarcaba una amplia variedad de vitaminas (A, E, B1, B2, B5, B6, B, C, D3, H, etcétera), consideradas esenciales para 
la nutrición y adicionadas a productos alimenticios y farmacéuticos. Dicho cártel compuesto por 13 compañías operó casi 10 años, fijando precios y asignando cuotas de mercado.

En Estados Unidos, la investigación condujo a la sanción de las firmas participantes en el cártel (Rhone-Pounelec quedó exenta de sanciones). Las multas aplicadas sumaron más de US\$ 1000 millones, donde Hoffman, La Roche y Basf tuvieron las sanciones más altas.

En Europa, las multas llegaron a una cifra récord de 885.5 millones de euros, ya que las firmas vinculadas con el cártel poseían una mayor participación de mercado en el negocio de las vitaminas, y por lo tanto, eran las mayores beneficiadas de la existencia del mismo. Esta agravante les significó un sobre cargo en las sanciones de un 50 y 30\% a La Roche y Basf, respectivamente. El resto de las firmas participantes obtuvieron una reducción entre el 35 y el 10\% (operó también una delación compensada).

Las legislaciones comparadas han enfrentado los procesos de cartelización, como los vistos anteriormente, incorporando figuras de amnistía empresarial que ayudan a detectar éstas prácticas colusorias o cárteles. En efecto, Estados Unidos en 1993-98, Alemania, Canadá y Reino Unido, en 2000; Francia en 2001, Suecia en 2002, Australia en 2003 y Japón en 2006.

\section{VI. ÓRGANOS REGULADORES DE LA COMPETENCIA EN LA REGIÓN}

La característica general de los órganos reguladores es que la mayoría de ellos, están alojados en el Poder Ejecutivo, con mayores o menores autonomías técnicas, financieras y de gestión; por ejemplo, Brasil regula la competencia a través del Consejo Administrativo de Defensa Económica (CADE); Argentina tiene la Comisión Nacional de Defensa de la Competencia, y por Ley 25156, recientemente introdujo reformas, estableciendo el control previo de fusiones y adquisiciones y la creación del Tribunal de Defensa de la Competencia, con plena jurisdicción sobre los temas de la competencia; Costa Rica tiene la Comisión de Promoción de la Competencia (Coproco) que identifica, investiga, acusa y 
sanciona las prácticas anticompetitivas, cuyas resoluciones pueden ser impugnadas ante los tribunales jurisdiccionales; Perú también tiene un órgano de similares características, en todos los cuales se le cuestiona el carácter de ser juez y parte en el manejo de la prevención y/o sanción de las prácticas anticompetitivas.

En América Latina, las legislaciones de Brasil y Chile han reformado sus leyes de competencia, incorporando esquemas de amnistía empresarial, cercana a la delación compensada.

Dos presupuestos básicos requieren establecerse para que opere la delación compensada:

a) Fuertes y cuantiosas multas calculadas en porcentaje sobre las utilidades anuales de las empresas, y

b) Privación de libertad para los ejecutivos que intervienen en la colusión o cárteles.

\section{Delación compensada en Chile}

Chile reformó su Ley de Competencia en 2009, y plasmó la delación compensada, que supone exentar o atenuar la multa de la empresa, que siendo parte de una colusión, la denuncia ante la autoridad, entregando antecedentes y pruebas, desarticulando así dicho cártel o colusión. ${ }^{40}$

En efecto, la delación compensada es un instrumento eficaz para la detección y disuasión de cárteles en el mundo; valga mencionar como ejemplo un requerimiento por colusión presentado por la Fiscalía Nacional Económica (FNE) ante el Tribunal de Defensa de la Libre Competencia en 2004, en contra de Whirpool S. A. y Tecumseh Do Brasil Ltda, principales proveedoras de compresores herméticos de baja potencia para la fabricación de refrigeradores en el mercado chileno. La colusión entre tales empresas ha dañado a la industria chilena de fabricación de refrigeradores de uso doméstico, a los comercios que requieren de equipos de refrigeración y a los consumidores que han adquirido refrigeradores.

40 Guía Delación de la Fiscalía Nacional Económica. Gobierno de Chile, disponible en http: / / www.fne.cl/?content=guia_delacion, consultada el 30 de agosto de 2010. 
Este es el primer requerimiento presentado por la FNE en que se utiliza la delación compensada como herramienta para detectar un cártel, constituyendo un hito en la historia de la persecución de cárteles de Chile. Hasta el momento Tecumseh Do Brasil es la primera empresa que ha cumplido con los requisitos legales para acceder al beneficio de la exención de multa.

\section{Tribunal de la Libre Competencia en Chile (TDLC)}

El TDLC de Chile fue creado el 14 de noviembre de 2003, mediante la Ley 19.911, teniendo su última modificación a través de la Ley 20.3.601 del 13 de julio de 2009, su naturaleza jurídica es la de un órgano de jurisdicción especial independiente para administrar justicia con relación a conflictos de relevancia jurídica respecto a las conductas anticompetitivas, lo forman 5 ministros y dos suplentes, de los cuales 3 son abogados, y 2 economistas. El Tribunal está sujeto a la superintendencia correctiva y discrecional de la Corte Suprema de Justicia en virtud del principio de jerarquía o grado jurisdiccional.

ElTDLC tiene facultades de conocer, dictar instrucciones y proponer modificaciones o derogaciones de los preceptos legales y reglamentarios contrarios a la libre competencia. Sus facultades principales son de carácter jurisdiccional, pues recibe las acusaciones de parte de la FNE $\mathrm{y} / \mathrm{o}$ de particulares con interés procesal en materia de competencia. ${ }^{41}$

En estos momentos el Tribunal conoce la solicitud de delación compensada explicada anteriormente.

\section{CONCLUSIONES}

Frente a los cambios en el entorno económico mundial y los nuevos esquemas comerciales que imponen las grandes potencias económicas,

${ }^{41}$ González, Aldo, La delación compensada o amnistía en la lucha anti-cárteles, trabajos de investigación en políticas públicas, núm. 2, enero, 2007. Disponible en http://scholar.google.com $/$ scholar? $\mathrm{hl}=$ es\&lr $=\& q=$ related:z1 kzm19aRCcJ:scholar. google.com $/ \& u m=1 \& i e=U T F-8 \& e i=$

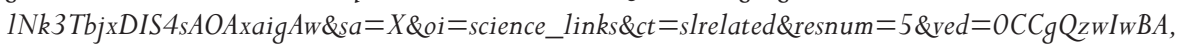
consultada el 2 de diciembre de 2010. 
surge la formación de bloques regionales que pretenden buscar beneficio en conjunto para las economías de la región, prescindiendo de discriminación entre unidades económicas del área integrada.

En el contexto globalizado, las economías de los Estados, identifican en la integración económica, posibilidades de mejorar sus niveles competitivos en materia de comercio exterior, de aprovechar sus ventajas comparativas y desarrollar una mejor calidad de vida de sus habitantes. ${ }^{42}$

De este modo, la integración surge como un proceso necesario en la inserción global de las economías locales que muy difícilmente podrían lograr privándose del contacto y cooperación con sus vecinos. Efectivamente, la internacionalización de la economía depende del intercambio comercial de bienes y servicios.

Es en el actual escenario mundial de creciente apertura comercial y existencia de legislaciones pro-competencia - tendencia extendida a través de la suscripción de tratados de libre comercio-, y una ausencia de leyes punitivas, que se conduce a la colusión entre las empresas con el objetivo de la fijación de precios y adquisición de posiciones dominantes. Ello inhibe las ventajas del libre comercio y eficiencia de mercados. La colusión entre empresas para lograr dichos fines, es un fenómeno actual que encuentra, en la falta de mecanismos para sancionar tales prácticas, oportunidades de fortalecerse. Las economías de mercado deben contar con instrumentos legales avanzados que permitan proteger la competencia y actuar en forma efectiva sobre prácticas anticompetitivas.

En este marco, la amnistía para delatores de cárteles ha mostrado ser un instrumento efectivo en la lucha contra estas prácticas entre empresas a nivel internacional, como han demostrado ser los ejemplos de Brasil y Chile, este último con su Tribunal de Defensa de la Libre Competencia, de plena jurisdicción sobre los temas relacionados con esta materia, y Estados Unidos con sus acciones desarticulantes de los cárteles de vitaminas y grafito, donde se hizo uso de la delación compensada, que supone exentar o atenuar la multa de la empresa, que siendo parte de una colusión, la denuncia ante la autoridad, entregando antecedentes y pruebas de tales prácticas anticompetitivas.

42 Sobre todo aquellos que comparten necesidades, problemáticas y metas compatibles. 
Es por ello que no debe perderse de vista la importancia del papel de los Estados en el diseño y estructuración de políticas públicas y estrategias, que permitan a sus naciones lograr los resultados políticos, económicos, culturales y sociales, para alcanzar un mejor nivel de vida para sus gobernados, sin sacrificar en la suscripción de tratados, un desarrollo micro por uno macroeconómico ya sea nacional o extranjero, sino hacer uso de tales instrumentos internacionales para crear y en su caso fortalecer órganos y organismos de control sobre estas prácticas, logrando así el crecimiento y desarrollo económico para los consumidores nacionales, a quienes los procesos de integración deben favorecer.

\section{BIBLIOGRAFÍA}

Alperstein Lerman, Aida, Multilateralismo y regionalismo en América Latina, México, Miguel Ángel Porrúa, Universidad Autónoma Metropolitana, 2001.

Bela Belassa, J. D., Teoría de la integración económica, México, UTEHA, 1943.

Buzo DE la PeÑA, Ricardo Marcos, La integración de México al Mercado de América del Norte, México, UAM Azcapotzalco, 1997.

Boletín México Exporta, núm. 7, Secretaría de Economía, www.aladi.org, consultado el 28 de agosto de 2010.

Calva, José Luis, México, Más allá del neoliberalismo, México, Plaza y Janes, 2000.

Cosío Díaz, José Ramón, Derecho y análisis económico, México, Fondo de Cultura Económica, 2002.

Cuadrado Roura, Juan R., Política económica. Objetivos e instrumentos, 2a. ed., Madrid, McGraw-Hill, 2001.

De la ReZA, Germán A. (coord.), México más allá del TLCAN. Competitividad y diversificación de mercados, México, UAM Azcapotzalco, Plaza y Valdés, 2004.

Estudios Económicos 2007, OCDE, octubre de 2007, www.sre.gob.mx/ ocde/, consultada el 26 de agosto de 2008. 
GonzÁlez de Cossío, Francisco, Competencia económica. Aspectos jurídicos y económicos, México, Porrúa, 2005.

ral. University of Chicago, 2003.

Himmer, Waldemar y Prager, Diezmar, GATT, ALADIY NAFTA, Buenos Aires, Ciudad Argentina, 1998.

LÓPEZ VILlAFAÑE, Víctor, Globalización, y regionalización desigual, México, Siglo XIX, 1997.

Nieto Solís, José Antonio, Introducción a la economía de la Comunidad Europea, España, Siglo XIX, 1991.

PÉREZ Miranda, Rafael J., Régimen de la competencia y de los monopolios.

Un enfoque de derecho económico, México, Porrúa, 2005.

Plano, Jack C. y Olton, Roy, Diccionario de Relaciones Internacionales, México, Limusa-Noriega Editores, 1991.

Roldán Xopa, José y Mena Labarthe, Carlos, Competencia económica. Estudios de derecho, economía y política, México, Porrúa/ITAM, 2007.

SÁnchez DaZA, Alfredo, Procesos de integración económica de México y el mundo, México, UAM Azcapotzalco, Ediciones Eco, 2005.

Smith, Cintia Pussetto, "La política comercial de Estados Unidos. Una contradicción entre comercio libre y comercio justo", Comercio Exterior, México, vol. 53, núm. 3, 2003, p. 271.

WITKER, Jorge, "La agenda social del ALCA", en varios autores, Hacia un nuevo derecho del trabajo, México, UNAM, 2003

, El derecho de la competencia económica en el TLCAN, México, UNAM-Porrúa, 2003.

, Las reglas de origen en el comercio internacional contemporáneo, México, UNAM, Instituto de Investigaciones Jurídicas, 2006. , Derecho de la competencia en América (Canadá, Chile, Estados Unidos y México, Santiago de Chile, Fondo de Cultura Económica, 2000. Zapatero, Pablo, Derecho del Comercio Global, España, Garrigues Cátedra, Universidad de Navarra, Thomson Civitas, 2003. 